\title{
ANNE CARSON E A VERDADE SOBRE DEUS
}

\section{ANNE CARSON AND THE TRUTH ABOUT GOD}

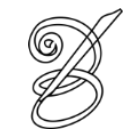

Traduzido por:

Julia Raiz do NASCIMENTO*

Universidade Federal do Paraná

Curitiba, Paraná, Brasil

Resumo: Apresentação da tradução inédita de três poemas da série "A Verdade Sobre Deus" do livro Glass, Irony \& God (1995) da escritora canadense Anne Carson. A escolha destes três poemas tem como objetivo apresentar ao público leitor brasileiro procedimentos estéticos que a autora lança mão em seus poemas para operar uma ampliação do imaginário sobre Deus. Pensando que a palavra Deus está, hoje no Brasil, na boca dos ministros e ministra de Estado, parece relevante saber como as/os poetas manipulam esse imaginário coletivo e como isso aparece nas escolhas tradutórias de textos para o português brasileiro.

Palavras-chave: Anne Carson. Literatura escrita por mulher. Tradução. Poesia canadense. Deus.

Abstract: Presentation of an unpublished translation of three poems from the series "The Truth About God" in the book Glass, Irony \& God (1995) by Canadian writer Anne Carson. By choosing to translate these three poems we aim to present the Brazilian reader with aesthetic procedures that the author uses in her poems to expand the imaginary about God. Considering that the word God is, today in Brazil, in the mouths of high-level government officials, it seems relevant to know how poets manipulate this collective imaginary and how it appears in the translation choices of texts into Brazilian Portuguese.

Keywords: Anne Carson. Literature written by women. Translation. Canadian Poetry. God.

RECEBIDO EM: 18 de fevereiro de 2020

ACEITO EM: 25 de fevereiro de 2020

PUBLICADO EM: março 2020 

\& God (1995) de Anne Carson. Apresento aqui a tradução inédita de três poemas da série: "Mulher de Deus", "Justiça de Deus" e "Teoria Sobre o Cristo de Deus". A escolha de traduzir estes poemas deu-se, principalmente, porque a repetição da palavra Deus nos títulos revela uma característica predominante na produção de Anne Carson, que é a de se desdobrar sobre um núcleo de interesse. Isso acontece com Deus nesta série, com a questão do sono no ensaio "Every Exit is an Entrance (A Praise of Sleep)", com a presença da cidade na série "The Life of Towns", e os exemplos envolvem vulcões e a cor vermelha e são muitos. É, portanto, um procedimento recorrente na escrita da autora, o de acionar o que podemos chamar de núcleo ou ponto de obsessão do qual deriva várias torções criativas. É assim que Anne Carson se permite reimaginar passagens bíblicas - especialmente o livro de Gênesis em "Mulher de Deus" -, propor relações do Criador com outras criaturas como acontece com a libélula em "Justiça de Deus" ou realocar Deus num conflito atual, no caso o movimento migratório de cidadãos/ãs mexicanos/as para os Estados Unidos e o impacto desse movimento nas línguas compartilhadas, em "Teoria Sobre o Cristo de Deus”. Assim, a tradução destes três poemas é uma tentativa de apresentar ao público leitor brasileiro a mente afiada de Anne Carson e as várias estratégias criativas que ela lança mão em seus poemas para operar uma ampliação do nosso imaginário sobre Deus. Pensando que a palavra Deus está, hoje no Brasil, na boca dos ministros e ministra de Estado, me parece relevante saber como as/os poetas manipulam esse imaginário coletivo.

\section{Sobre a autora}

Anne Carson ${ }^{1}$ (Toronto, 1950) é poeta, ensaísta, tradutora e, há mais de trinta anos, professora de estudos clássicos em diversas universidades norte-americanas como McGill Univesity em Montréal, Canadá, e University of Michigan, EUA. Carson publicou poemas, ensaios, libretti, crítica de prosa, romances em versos, textos teatrais - uma vasta produção que mistura gêneros textuais e literários de difícil classificação. É também conhecida por suas traduções do grego clássico, entre elas Antigonick e a trilogia An Orestia, que geram profícuas discussões sobre os limites entre tradução, reescrita e adaptação. Seus livros mais comentados são os premiados Men in the Off Hours (2000) e Red Doc > (2013) que são objetos de pesquisas na pós-gradução em universidades da América do Norte. No Brasil, o único livro publicado da autora é $O$ método albertine (trad. Vilma Arêas) pela Ed. Jabuticaba, 2017. 


\section{Sobre a tradutora}

Julia Raiz (São Paulo, 1991) é pesquisadora da área de Estudos Feministas da Tradução. No doutorado traduz os ensaios do livro Decreation da escritora canadense Anne Carson. Edita os blogs literários Totem \& Pagu (firrma de poesia) e Pontes Outras, dedicado à tradução de literatura escrita por mulheres. Participa em Curitiba do grupo de criação literária membrana sediado na Casa Selvática. Seu livro de estreia diário: a mulher e o cavalo saiu em 2017 pela Contravento editorial, publicou também o megamini $p / v c$ pela editora 7Letras.

\section{God's Woman}

Are you angry at nature? said God to His woman.

Yes I am angry at nature I do not want nature stuck

up between my legs on your pink baton or ladled out like geography whenever your buckle needs a lick.

What do you mean Creation?

God circled her.

Fire. Time. Fire.

Choose, said God.

\section{Mulher de Deus}

Você tá brava com a natureza? disse Deus pra Sua mulher.

Sim eu tô brava com a natureza eu não quero a natureza enfiada

no meio de minhas pernas pelo seu bastão rosa

ou oferecida como geografia toda vez

que sua fivela precisar de uma lambida.

O que você quer dizer com Criação?

Deus a circulou.

Fogo. Tempo. Fogo.

Escolha, disse Deus.

(CARSON, 1995, p. 46) 


\section{God's Justice}

In the beginning there were days set aside for various tasks.

On the day He was to create justice

God got involved in making a dragonfly

and lost track of time.

It was about two inches long

284 with turquoise dots all down its back like Lauren Bacall.

God watched it bend its tiny wire elbows

as it set about cleaning the transparent case of its head.

The eye globes mounted on the case

rotated this way and that

as it polished every angle.

Inside the case

\section{Justiça de Deus}

No começo existiam dias separados pra variadas tarefas.

No dia em que Ele criaria a justiça

Deus meteu-se a fazer uma libélula

e perdeu a noção do tempo.

Tinha uns cinco centímetros

com pintas turquesas por toda as costas como a Lauren Bacall.

Deus assistiu o dobrar de seus finos cotovelos de arame

enquanto ela iniciava a limpeza da transparente cápsula de seu crânio.

Os glóbulos oculares montados na cápsula girando pra cá e pra lá polindo cada ângulo. Dentro da cápsula 
which was glassy black like the windows of a downtown bank

God could see the machinery humming

and $\mathrm{He}$ watched the hum

travel all the way down turquoise dots to the end of the tail

and breathe off as light.

Its black wings vibrated in and out.

(CARSON, 1995, p. 49) que era de um preto translúcido como as janelas de um banco no centro

Deus podia ver a maquinaria murmurando

e Ele assistiu ao murmúrio

viajar o caminho até embaixo as pintas turquesas no final da cauda

e expirar como luz.

\section{God's Christ Theory}

God had no emotions but wished temporarily

to move in man's mind

as if He did: Christ.

Not passion but compassion.

\section{Teoria Sobre o Cristo de Deus}

Deus não tinha emoções mas desejava por ora

mover-se na mente humana

como se Ele fizesse: Cristo.

Não paixão mas compaixão. 
Com-means "with."

What kind of withness would that be?

Translate it.

I have a friend named Jesus

from Mexico.

His father and grandfather are called Jesus too.

They account me a fool with my questions about salvation.

\section{6}

They say they are saving to move to Los Angeles.
Com-significa "junto."

Que tipo de junção seria essa?

Traduza.

Eu tenho um amigo chamado Jesus

do México.

Seu pai e o pai de seu pai chamam Jesus também.

Eles me acham uma boba com minhas perguntas sobre salvação.

Eles dizem que estão salvando pra mudar pra Los Angeles.

(CARSON, 1995, p. 51)

\section{REFERÊNCIAS}

CARSON, Anne. The Truth About God in Glass, Irony and God. New York: New Directions, 1995.

\footnotetext{
* Julia Raiz do NASCIMENTO - Graduada em Letras (2012) pela Universidade Estadual de Maringá (UEM). Mestre (2016) e doutoranda em Estudos Literários (2016) pela Universidade Federal do Paraná. Bolsista de Produtividade em Pesquisa da CAPES. Curitiba, Paraná, Brasil.

Currículo acadêmico: http://lattes.cnpq.br/5861489774184211

ORCID: https://orcid.org/0000-0003-4966-9568

E-mail: ju_raiz@yahoo.com.br

${ }^{1}$ Mais informações sobre a autora

https://poets.org/poet/anne-carson

https://www.brickbooks.ca/reviews/biography-of-anne-carson-reviewed-by/

https://www.nytimes.com/2013/03/17/magazine/the-inscrutable-brilliance-of-anne-carson.html
} 
https://www.poetryfoundation.org/poets/anne-carson

https://www.theglobeandmail.com/arts/the-unbearable-lightness-of-anne-carson/article769906/

\section{Entrevistas com a autora}

http://www.thewhitereview.org/feature/interview-anne-carson/

https://brickmag.com/an-interview-with-anne-carson/ 